\title{
The history of ergot of rye (Claviceps purpurea) III: 1940-80
}

\begin{abstract}
MR Lee
Emeritus Professor of Clinical Pharmacology and Therapeutics, University of Edinburgh, Edinburgh, UK

ABSTRACT The period 1940-80 in the history of ergot was dominated by two investigators, Arthur Stoll and Albert Hofmann. There was great excitement when their group isolated from ergot preparations the powerful psychotropic agent lysergic acid diethylamide (LSD). It was thought that this substance would help to find the cause of schizophrenia and other psychotic disorders, but it would prove to be a great disappointment and Hofmann would say later, in private, that he regretted having spent so much time on the compound. By contrast, bromocriptine, derived from ergocriptine, would prove a pivotal substance in our knowledge of dopamine receptors in the central nervous system. It is widely used for the suppression of lactation, the treatment of prolactinomas and the management of Parkinson's disease.
\end{abstract}

KEYWORDS Bromocriptine, dopamine receptors, ergot, Albert Hofmann, lysergic acid diethylamide, psychosis

DECLARATION OF INTERESTS No conflict of interests declared.

During the Second World War the pharmaceutical industry in the combatant countries was turned over largely to work on blood products, chemotherapeutic agents and nerve gases and their antidotes. In contrast, Swiss researchers continued to work on more classical areas of pharmacology, including ergot.This was particularly so at the Sandoz facility at Basel, where two brilliant chemists, Arthur Stoll (Figure I) and Albert Hofmann (Figure 2), were successively directors of research.'.2

As their work progressed it transpired that all the naturally occurring ergot alkaloids were derived from a single building block, lysergic acid diethylamide (LSD). This compound has a tetracyclic indole ring system (Figure 3). Substitution in this basic structure determines the type and action of the ergot alkaloid that is produced. For example, with ergotamine the substituent is a complex tripeptide, which determines that its predominant physiological effect is vasoconstriction. ${ }^{3}$ In comparison, ergometrine has a simple substituent that consists of 2-aminopropanolol. ${ }^{3}$ This important side chain ensures that it has greater solubility in water and a more pronounced effect on uterine contraction.

\section{LYSERGIC ACID DIETHYLAMIDE}

The story of LSD began seriously in 1938, when Stoll and Hofmann succeeded in their attempts at a partial synthesis of ergometrine. ${ }^{4}$ The main objective of their work had been to synthesise the oxytocic alkaloid, but in the course of these studies they also produced other amides of lysergic acid. They were looking inter alia for a compound that might resemble the powerful analeptic agent nikethamide, also known as Coramine ${ }^{\circledast}$ (Figure 3). One of the compounds that emerged as a by-product was d-lysergic

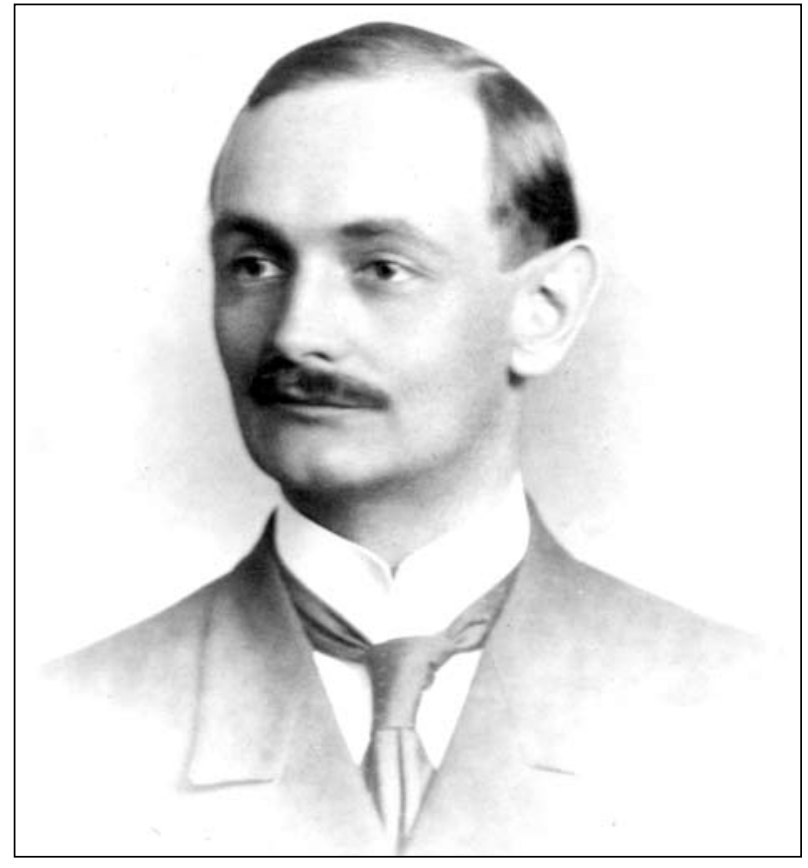

FIGURE I Arthur Stoll (1887-197I), one-time director of research at Sandoz. (With kind permission of Novartis International AG.)

acid diethylamide (d-LSD). However, LSD was very disappointing in its activity both as an analeptic and as an oxytocic. As a result of these findings, LSD was abandoned. This decision was also influenced by results from animal experiments where severe toxic reactions such as ataxia, paralysis and catatonic behaviour were observed.

Five years later Hofmann decided to take up the problem of LSD again and synthesised a new batch. ${ }^{2}$ While he was working in the laboratory on the new material, he was 


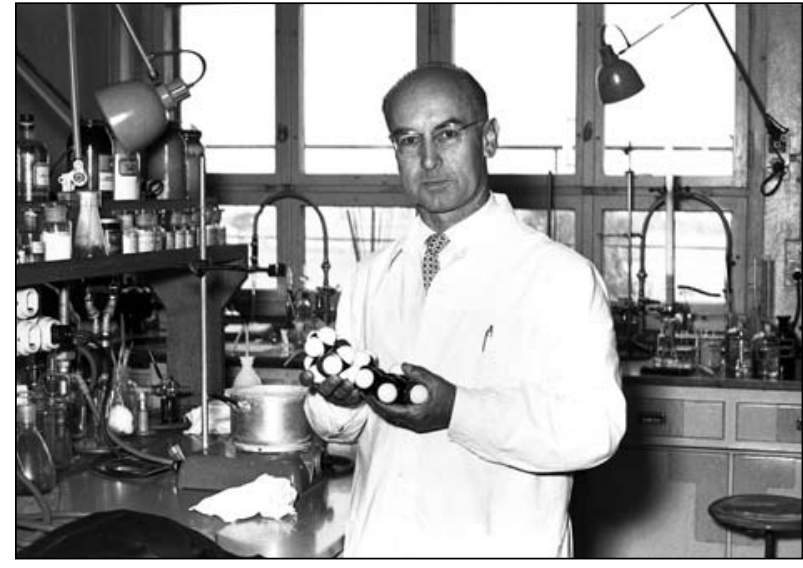

FIGURE 2 Albert Hofmann (1906-2008) followed Stoll as director of research at Sandoz. He reisolated lysergic acid diethylamide and studied the effects of this compound on himself. (With kind permission of Novartis.)

overcome by a remarkable but not unpleasant state of intoxication: 'There surged upon me an uninterrupted stream of fantastic images of extraordinary plasticity and vividness, accompanied by an intense kaleidoscopic play of colours.' ${ }^{2}$ This startling condition passed off gradually over the next few hours.

Hofmann surmised immediately that the LSD he had been working on could have been responsible for this curious hallucinatory attack. He also concluded that he must have been contaminated by a very small dose which had gained access to his body either by ingestion or inhalation. Accordingly, he decided to embark upon a programme of experiments in which he took gradually increasing doses of LSD by mouth. The first dose he took seemed minute, $250 \mu \mathrm{g}$. In the light of many further observations it was, in fact, a large overdose. We now know that the threshold dose to produce an effect is approximately $50 \mu \mathrm{g}$.

The effects of this first deliberate dose were indeed dramatic! He developed vertigo, visual hallucinations and motor agitation, followed by paralysis. Everything in the vicinity seemed to sway backwards and forwards or from side to side. Later on, colours appeared to change very rapidly from one hue to another, which was emotionally very unpleasant. Another particular feature was that sounds, for example that of a passing car, were transformed into optical effects, the phenomenon of synaesthesia. Gradually, over a period of six to eight hours, all these effects wore off and, after a good sleep, Hofmann's mental function returned to normal. ${ }^{5,6}$

The publication of these results in 1947 caused something of a sensation. ${ }^{6}$ Academic departments of psychiatry, psychology and neurobiology seized upon the compound and thousands of experiments were carried out on animals, normal volunteers and psychotic patients. ${ }^{7}$ After an initial wave of enthusiasm it was found that the drug

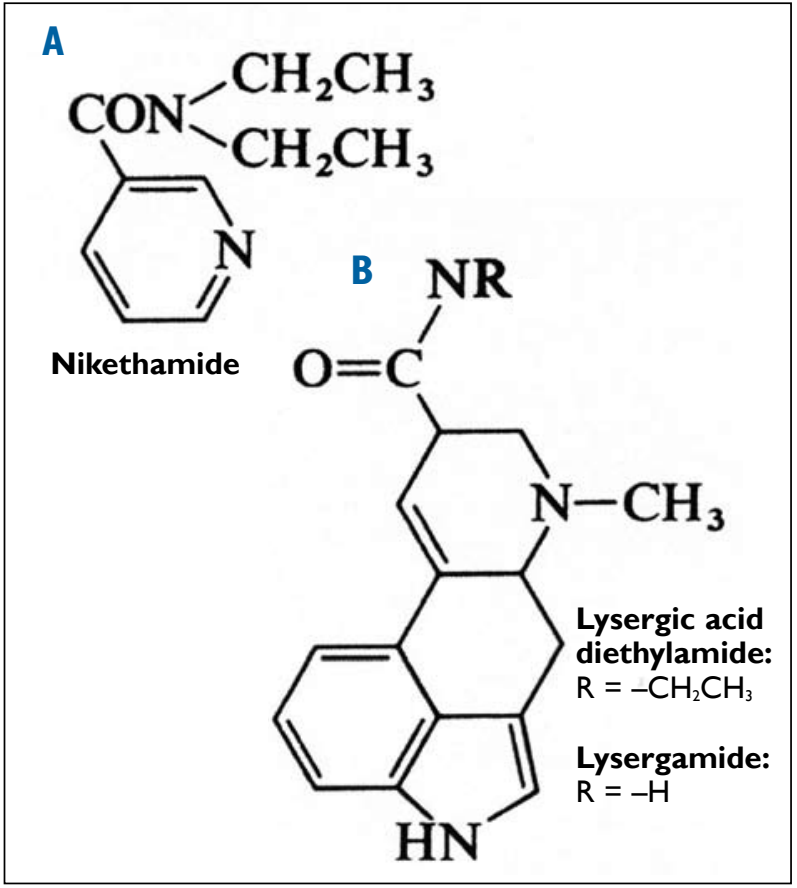

FIGURE 3 The chemical structures of nikethamide (A), lysergic acid diethylamide and lysergamide (B).

appeared to make psychotic patients worse and in normal individuals could induce a damaging psychiatric state, particularly if taken repeatedly in large doses., ${ }^{8,9}$ This induction of a permanent psychotic reaction seemed to be associated with uncontrolled consumption of the drug in adolescents who had obtained the compound illicitly. Not only were there chronic psychiatric risks, but a number of individuals had serious acute reactions even on the first dose. In these adverse reactions a number of dangerous accidents were reported either by the individual or by witnesses. The hallucinations can take on a menacing quality and the person may suffer from delusions of persecution. In this state the subject can kill himself or others. One bizarre and damaging delusion that has often been reported is that individuals think they can fly. In their intoxicated state they would leap from high places such as windows, balconies and roofs with the inevitable disastrous consequences. ${ }^{8,9}$

How does LSD exert its dramatic effects in the brain? It seems to have a powerful action on serotoninergic and dopaminergic receptors in both the peripheral and central nervous system in particular (in order to generate visual and auditory hallucinations). In this way it is reminiscent of both ergotamine ${ }^{3}$ and bromocriptine (see below).

Hofmann admitted later in his life that he had spent far too much of his time on LSD., ${ }^{5,10} \mathrm{He}$ was, no doubt, seduced by the idea that if he could produce a schizophrenia-like syndrome with LSD he could not be far from finding the cause of the psychosis and, perhaps, a cure. However, the drug-induced syndrome did not 
resemble schizophrenia exactly; in particular, in humans there was no blunting of affect or induction of catatonic states. Lysergic acid diethylamide was, of course, not a total loss: the basic chemical knowledge generated in regard to this structure and the ergolines would enable the synthesis of bromocriptine and other compounds, which would have helpful therapeutic effects in a range of clinical disorders. Hofmann died in 2008 at the advanced age of $102 .{ }^{10} \mathrm{He}$ was one of the greatest analytic and synthetic chemists of the twentieth century and his contribution will not be forgotten.

\section{Ololiuqui and morning glory}

For a period in the 1950s and 1960s Hofmann became, to a degree, obsessed with the study of hallucinogenic drugs. His interest was further stimulated when he was sent some seeds of the 'magic' Mexican plant Rivea corymbosa. Known to the Aztecs as ololiuqui, this plant had been used in religious practices and medicinal therapy for thousands of years. Hofmann's first studies demonstrated that an extract of Rivea contained an indole ring, which suggested a basic ergoline structure. To his great surprise, further analysis showed that the extract contained ergot alkaloids of various sorts: lysergic acid amides and other derivatives of lysergic acid." These revelations, when published, were greeted with varying degrees of disbelief, scorn and even amusement. It was generally considered that the results must have been produced by contamination in his laboratory, which was working actively on other preparations of ergot. Hofmann was irritated by these slurs on his professional competence as an analytical chemist, but he was vindicated when his results were eventually confirmed in other centres."

In 1965, Hofmann published findings on another hallucinogenic plant: Ipomoea violacea, a member of the family Convolvulaceae, related to morning glory. ${ }^{12}$ It also was found to contain ergot alkaloids, in particular ergometrine. These two plants, Rivea and Ipomoea, are a remarkable example of convergent evolution, where the building blocks of the ergot alkaloids and the amides of lysergic acid appear in these higher plants. This must generate a selective advantage to the three genera Claviceps, Rivea and Ipomoea. Presumably insects and grazing animals are, to a degree, repelled by their bitter taste and central nervous system toxicity, which occurs even at very low doses.

\section{BROMOCRIPTINE (2 BROM0- $\alpha-E R G O C R Y P T I N E)$}

Drug development occurs in a variety of ways. Sometimes it is a methodical, painstaking, step-by-step process as in the case of Paul Ehrlich's compound 606, a powerful arsenical which represented more than 600 modifications of the basic compound. In contrast, the development of bromocriptine at Sandoz represented a combination of hard work and serendipity.

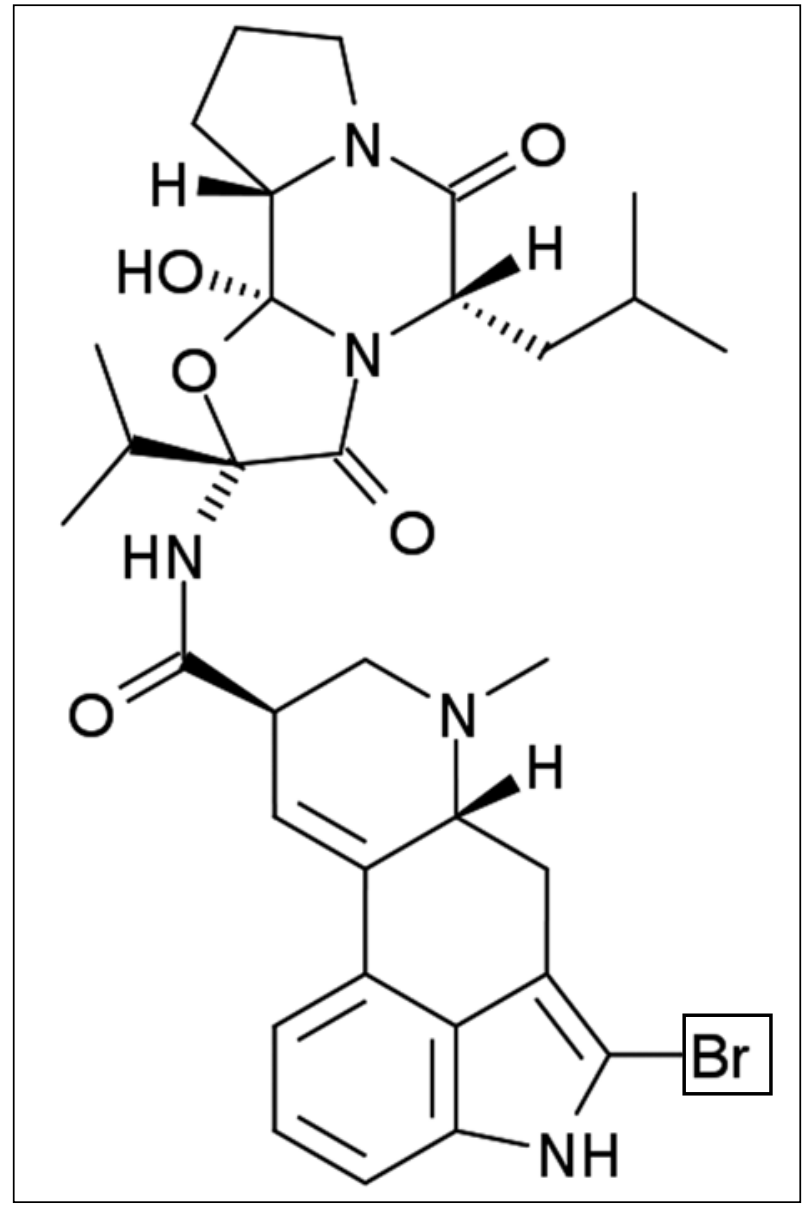

FIGURE 4 The chemical structure of bromocriptine.

The history of the drug started in Israel. In the 1950s Moses Shelesnyak of the Weizmann Institute of Sciences in Tel Aviv started a series of experiments in rats to find a compound that would interfere with the process of implantation of the ovum in this animal. ${ }^{13}$ Two compounds commanded his attention, ergometrine and 'ergotoxine'. ${ }^{3}$ It should be remembered that 'ergotoxine' was thought at this time to be a pure compound and not, as transpired later, a mixture of three alkaloids. Ergometrine had little effect on ovum implantation, whereas 'ergotoxine' was extremely active. Eventually, after an extensive series of studies, the Tel Aviv group concluded that 'ergotoxine' was not acting at the level of the uterus but in the hypothalamus, where it inhibited prolactin secretion. As a consequence, progesterone secretion from the ovary was depressed and the ovum failed to implant. ${ }^{13}$ At the time these important observations were made there was no assay available for plasma prolactin, and the findings were largely ignored by the scientific world. However, the workers at Sandoz were intrigued and repeated the experiments with the pure alkaloids derived from 'ergotoxine'. Two of these, ergocriptine and ergocornine, proved to be active in the inhibition of implantation of the ovum.

In the meantime, the structure of the hormone prolactin was established and sensitive radioimmunoassays of this 
trophic polypeptide became available. Edward Flückiger at Sandoz began to search for an ergot alkaloid that would be active by mouth and would specifically inhibit prolactin secretion by the pituitary. Initially the compounds produced by his group for assay had far too short a halflife to have any possible clinical value. After many disappointments, success came in 1965 with the synthesis of the ergoline derivative bromocriptine ( 2 bromo- $\alpha$ ergocriptine) (Figure 4). ${ }^{14}$ This compound had little action at the adrenergic and serotonergic receptors but marked agonist activity at those for dopamine; that is, it was a relatively 'clean' drug. Indeed, the substance helped to delineate these receptors both centrally and peripherally $\left(D_{1}\right.$ and $D_{2}, D A_{1}$ to $D_{4}$ respectively). Extensive clinical studies were then carried out over the next 20 years to attempt to establish a role for bromocriptine, both as an alternative to L-dopa in Parkinson's disease and in its own right in endocrine disorders.

The drug was in due course shown to be active in the following diverse disorders: puerperal and nonpuerperal lactation, prolactinomas, acromegaly and Parkinson's disease. All these positive therapeutic effects were mediated by activation of dopamine receptors in various areas of the brain, including the hypothalamus and pituitary, the basal ganglia and the substantia nigra. Looking back on ergot in medieval times, two phenomena had been observed which presaged modern-day advances: the first was that when nursing mothers contracted ergotism they lost their ability to lactate; and the second was that farmers used to keep milking cows away from rye pastures in the summer as the cereal could, when contaminated with ergot, stop their milk. ${ }^{15}$

\section{REFERENCES}

I Holmstedt B, Liljestrand G, editors. Readings in pharmacology. New York: Raven Press; 198I. p. 209-13.

2 Hofmann A. Ergot - a rich source of pharmacologically active substances. In: Swain T, editor. Plants in the development of modern medicine. Cambridge, MA: Harvard University Press; 1972. p. 236-60.

3 Lee MR. The history of ergot II: 1900-40.J R Coll Physicians Edinb 2009; 39:365-9.

4 Stoll A, Hofmann A. [Partial synthesis of alkaloids of the ergonovine type.] Helv Chim Acta 1943; 26:944-65. In German. doi:10.1002/ hlca. 19430260326

5 Hofmann A. LSD: my problem child. New York: McGraw Hill; 1980.

6 Stoll WA. [Lysergic acid diethylamide, a hallucinogen from the ergot group.] Schweiz Arch Neut 1947; 60:279. In German.

7 See http://www.erowid.org/references/refs.php for a complete list of $L S D$ research papers.

8 Smart RG, Bateman K. Unfavourable reactions to LSD: a review and analysis of the available case reports. Can Med Assoc J 1967; 97:|2|4-2|.

9 Cohen S. A classification of LSD complications. Psychosomatics 1966; 7:182-6.
Other ergoline drugs similar to bromocriptine have been synthesised, and this group now includes cabergoline, pergolide and lisuride. ${ }^{16}$ Since these drugs have come into widespread use, a number of unusual side effects have been described. These include psychotic episodes such as hallucinations (compare LSD), sudden onset of sleep, hypotension, hypertension and fibrotic actions (in particular in relationship to the valves of the heart). Vasospasm of the fingers and toes has also been described, which resembles Raynaud's phenomenon. However, these dopamine agonists still retain a definite place in the therapeutic armamentarium. In Parkinson's disease they are often used as second- or third-line drugs after an L-dopa/carbidopa combination and monoamine oxidase inhibitors such as selegiline. ${ }^{16}$ If George Barger and Henry Dale were alive today, I am sure that they would derive considerable satisfaction from the knowledge that out of the mixture 'ergotoxine' there had been developed first ergocriptine and then the powerful therapeutic entity bromocriptine, both of which have added immeasurably to our knowledge of the dopamine receptors. ${ }^{3}$

It has been difficult to compress the history of ergot into three short articles. Yet I hope that I have given a flavour of this fascinating fungus which has both stimulated and frustrated scientists for almost 200 years.

Acknowledgements I would like to thank Mr lain Milne and his colleagues at the Sibbald Library of the Royal College of Physicians of Edinburgh, Mrs May Gibb, Barlow Moor Books and the publications department of the College.
10 Obituary: Albert Hofmann. Daily Telegraph; 20 May 2008. Available from: http://www.telegraph.co.uk/news/obituaries/19/2485/ Obituary-Albert-Hofmann-LSD-inventor.html

II Hofmann A, Tscherter H. [Isolation of lysergic acid alkaloids from the Mexican drug ololiuqui (Rivea corymbosa (L.) Hall.f.).] Experientia 1960;16:414. In German. doi:10.1007/BF02178840

12 Stauffacher D, Tscherter H, Hofmann A. [lsolation of ergosine and ergosinine as well as agroclavine from seeds of Ipomoea argyrophylla Vatke (Convolvulaceae). 64. On ergot alkaloids (I)] Helv Chim Acta 1965; 48:1379-80. In German. doi:10.1002/ hlca. 19650480618

13 Shelesnyak MC. Ergotoxine inhibition of deciduoma formation and its reversal by progesterone. Am J Physiol 1954; 179:30I-4.

14 Flückiger E. The pharmacology of bromocriptine. In: Bayliss RIS, Turner P, Maclay WP, editors. Pharmacological and clinical aspects of bromocriptine (Parlodel). Tunbridge Wells: MCS Consultants; 1976. p. $12-26$.

I5 Giacomini GA. Traité philosophique et expérimental de matière médicale et de thérapeutique. Paris: Bureau de l'encyclopédie; 1839.

16 Joint Formulary Committee. British National Formulary. 57 ed. London: British Medical Association and Royal Pharmaceutical Society of Great Britain; 2008. p. 410-2. 